\title{
Feasibility and Optimization of Electrochemical Machining for 6061 Aluminum alloy
}

\author{
Dhia Ahmed Alazawi \\ Lecturer, Department of Mechanical Engineering, College of Engineering, Diyala University \\ Dhia.alazawi2@mail.dcu.ie
}

\begin{abstract}
The request depending on electrochemical machining (ECM) technique has progressed in a large scale according to different points of view such that; cost or energy consuming, environment protection, reliable performance etc. This work aims to predict and optimize ECM process parameters for important, economic and applicable material (6061 aluminum) by employing L9 Taguchi method as a design of experiment (DOE) approach. This has led to experimental designing, developing a mathematical model and optimizing the entire ECM operation. This was carried out by controlling the chosen process variables (voltage, flow rate speed and electrolyte concentration) in order to optimize and predict the responses namely material removal rate (MRR) and dissolution rate. ANOVA, 3D contour graphs and perturbation plots have been employed to identify the analysis of variance of each response as well as to show the significant model terms. The process parameters i.e. voltage, flow rate speed and electrolyte concentration have been ranged to be $15-25 \mathrm{~V}, 8-12 \mathrm{l} / \mathrm{min}$ and $3.36-7 \%$ respectively. In both cases of MRR and dissolution rate the voltage parameter has seen to be the prominent factor that affects the responses so as to investigate highest value of MRR and dissolution rate, $0.477 \mathrm{~g} / \mathrm{min}$ and $2.149 \mathrm{~mm} / \mathrm{min}$, respectively. This has been confirmed due to the results obtained from the ANOVA analysis which shows maximum Fvalu for the voltage in the MRR and dissolution rate such that; 921.91 and 1608.34 respectively. But, still there was a considerable enhancement in the MRR and dissolution rate due to the increment in the flow rate speed and electrolyte concentration. Model validation has been carried out and thus the results invistigated that all the considered models were adequate since the residuals in prediction of each response were ignored, because the residuals were semi-matched with the diagonal line. Optimizations of responses were performed in this work numerically by using two types of criteria (restricted and nonrestricted). According to these criteria, important increment in the MRR can be obtained which reaches $37 \%$. A considerable
\end{abstract}

enhancement has been obtained in the dissolution rate due to the comparison between the two criteria which results in increment by around $11 \%$ as well.

Keywords: Optimization, Electrochemical Machining, DOE

Paper History: Received: (9/10/2016), Accepted: (19/12/2016)

\section{Introduction}

In general, the electrochemical processes have good compatibility with a wide range of other processes in which different techniques are employed. They allow hybridization and hence their performance enhancement [1-7]. Electrochemical machining (ECM) represents economic and active technique for machining brittle metals as well as complex shapes that are difficult to machine by other traditional techniques. ECM usually depends on anodic electrochemical dissolution interaction between the tool and the work-piece [8]. In this process the work piece removes on the account of the tool due to the applied voltage and thus electrochemical oxidation and dissolution will take place. A vertical motion of the tool towards the work piece in an electrolyte solution will take place within the ECM operation. This leads to re-shape the work piece due to mass transport migration by using an appropriately shaped tool [9]. Wide scale of ECM benefits such as; excellent surface finish, no stress, long life service, no burrs generation, high metal removal rate...etc, have led this technique to take wide interest in industry. Therefore it has been employed in the industry of complex s components in defence and aerospace industries as well as in many other applications such as automotive, forging dies, electric and surgical components, and, recently, in miniature manufacturing [10]. Among the large scale of materials, aluminum alloys has been employed by many authors since it is easy to be machined by traditional technique due to the reduced hardness value and rise thermal inductance $[11,12]$. In fact, many researches on non-conventional techniques (ECM, EDM...etc) for several materials such as steel alloys, composite materials and titanium alloys have been carried out previously [13-16]. But the researches on optimization of aluminum alloys using the nontraditional techniques were very few. 
DAVE et al [17] employs Taguchi optimization approach to investigate the microholes produced on 1100 aluminum alloy using micro-electro-discharge machining. The process parameters were considered to be voltage in gap, capacitance, time, thickness of electrodes and electrode rotation as the responses were bottom radius, taper angle, top radius and electrode depletion. Despite this study underlined a prospective on some input and output variables on ECM of 1100 aluminum alloys, but it does not provide any information of underlying mechanisms. Burger et al. [18] have studied the machining parameters influence in terms of the change in MRR and surface roughness in ECM/PECM of nickel-base single-crystal alloy (LEK94). Bahre et al. [19] investigated the optimization of the pulse electrochemical machining (PECM) technique by RSM. The process parameters in this work were represented by voltage; pulse on time, frequency, feed rate and pressure and the MRR and surface roughness $(\mathrm{Ra})$ were the responses. This study indicated the prediction and optimization of MRR and Ra models using RSM.

However, when it is needed to produce a complex shaped component, the ECM found to be a successive technique that serves in terms of time and cost. For that, it is of necessity to comprehension the electrochemical machining of 6061 aluminum alloy in total. Regarding to the facts in above, the electrochemical machinability of 6061 aluminum has been investigated in terms of MRR and dissolution rate due to the influence of the process parameters (voltage, flow rate speed and electrolyte concentration). This was observed in order to aid the research society and the industry authors to investigate the behavior of 6061 aluminum alloy when it needs to be machined by ECM. Of importance, all the considered optimization results have been analyzed by means of plots showing the dependence of the objective function and constraints on the decision variables. These graphs were plotted by varying single decision variable at a time and keeping the values of other decision variables constant that were selected on the basis of one of the optimum solutions.

\section{Experimental design}

\section{Orthogonal experiment}

In the present work an orthogonal experiment has been employed to investigate the favorable parameters combination and the most affecting factors on MRR and dissolution rate for 6061 aluminum alloy. The experiments that follows L9 orthogonal array was planned accordingly.
The three processing parameters and three levels can be shown in Table 1. The complete experimental design matrix and the mixing levels for the considered nine experiments are presented in Table 2. MRR and the dissolution rate were selected to be the responses wherein the voltage, flow rate speed and the electrolyte concentration were selected to be the variables.

Table 1 Process parameters and design levels.

\begin{tabular}{|c|c|c|c|c|c|}
\hline \multicolumn{2}{|c|}{} & \multicolumn{3}{|c|}{ Levels } \\
\hline Variables & Code & Unit & -1 & 0 & 1 \\
\hline Voltage & A & V & 15 & 20 & 25 \\
\hline $\begin{array}{c}\text { Flow rate } \\
\text { speed }\end{array}$ & B & $1 /$ min & 8 & 10 & 12 \\
\hline $\begin{array}{c}\text { electrolyte } \\
\text { concentrati } \\
\text { on }\end{array}$ & C & $\%$ & 3. & 5. & 7 \\
& & & 36 & 18 & \\
\hline
\end{tabular}

Table 2 Design matrix.

\begin{tabular}{|c|c|c|c|c|c|}
\hline std & $\begin{array}{c}\text { voltage } \\
(\mathrm{V})\end{array}$ & $\begin{array}{c}\text { flow } \\
\text { rate } \\
(1 / \mathrm{min})\end{array}$ & $\begin{array}{c}\text { Electrolyte } \\
\text { Concentration } \\
(\%)\end{array}$ & $\begin{array}{c}\text { MRR } \\
(\mathrm{g} / \mathrm{min})\end{array}$ & $\begin{array}{c}\text { dissolution } \\
\text { rate } \\
(\mathrm{mm} / \mathrm{min})\end{array}$ \\
\hline 1 & 15 & 12 & 3.36 & 0.230 & 1.604 \\
\hline 2 & 25 & 12 & 3.36 & 0.375 & 2.03 \\
\hline 3 & 15 & 12 & 7 & 0.355 & 1.479 \\
\hline 4 & 20 & 10 & 5.18 & 0.318 & 1.824 \\
\hline 5 & 15 & 8 & 7 & 0.262 & 1.474 \\
\hline 6 & 25 & 8 & 7 & 0.385 & 1.944 \\
\hline 7 & 25 & 12 & 7 & 0.477 & 2.149 \\
\hline 8 & 15 & 8 & 3.36 & 0.160 & 1.499 \\
\hline 9 & 25 & 8 & 3.36 & 0.282 & 1.769 \\
\hline
\end{tabular}

\section{Experimental work}

\section{Tool; work piece and electrolyte description}

In the present work, a rectangular block of 10 $\mathrm{cm} \times 5 \mathrm{~cm}$ and $0.3 \mathrm{~cm}$ thickness made of 6061aluminum has been selected to be the work-piece. The tool has been chosen as a rod of $5 \mathrm{~mm}$ diameter as it is made of AISI4340 stainless steel. A silicon carbide (SiC) paper (up to P1200) was primarily used for grinding the specimens as well as they have been polished in order to obtain a mirror-like surface by using diamond suspension. The mixed $\mathrm{NaCl}$ and water liquid (with different concentrations) has been employed as an electrolyte solution. This has been carried out since it has no passivation impact on the workpiec surface.. A digital gauge was 
employed to measure the weight reduction before and after carrying out ECM process.

\section{Electrochemical machining (ECM) setup}

In this work, an ECM apparatus has been designed and manufactured to carry out the desired machining experiments. Figure 1 shows the ECM apparatus which mainly consists of different instruments that can do several functions necessary for carrying out the electrochemical operation such that:

1. Tool feeding device: Provides the required feeding by control the vertical movement of the machining tool.

2. Electrolyte pump: Pumps the electrolyte from the storage tank towards reaction chamber.

3. Flow meter: Controls the flow of electrolyte from storage tank towards reaction chamber.

4. Electrolyte tank: Stores the electrolyte for recycling to the reaction chamber

5. Reaction chamber: The machining operation is achieved in this part of ECM and the required chemical reaction can carry out 6. Power supply (voltmeter and control circuit): provides the current that is required for achieving the electrochemical reaction and this was carried out by forcing the electrons to move from the workpiece through the electrolyte to the tool. A D.C welding machine with variable voltage of $10-50 \mathrm{~V}$ has been employed as a power supply in this work.

7. Frame: handles all the apparatus components

In general, the work piece has been installed in the machining chamber fixedly. The cathode has been selected to be the tool and the workpiece represents the anode. The tool has been designated to carry out the vertical up/down movement with the assist of driving feeding system. Electrolyte was pumped through the machining gap from the channel which is inside the chamber. Within the process, the cathode tool will vertically moves toward the workpiece and the material removes continuously.

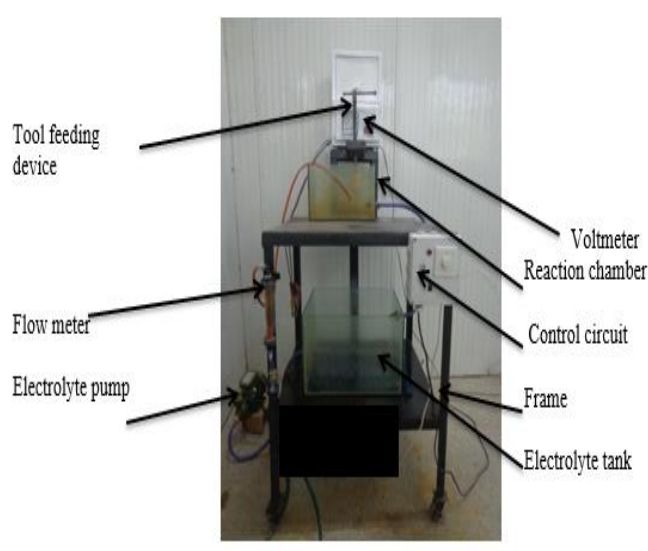

Figure 1: shows the ECM manufactured device

\section{Empirical concepts and calculations}

The Electrochemical machining (ECM) represents a non-conventional machining technique through which the material removes by anodic dissolution mechanism within the electrolysis process. Hence, the considered specimen can face gradual machining and gets precipitated as sludge. In addition, no residence of coating on the tool, only hydrogen gas promotes at the cathodic-tool. According to the required metal-electrolyte combination, electrolysis has included the dissolution of aluminum from the anode, and the generation of hydrogen at the cathode. This process continues and the tool reduplicates its shape on the workpiece or in other word on the anode [20].

In the present work, D.C. voltage of (15-25 volts) has been employed through the interelectrode gap (IEG) between pre-shaped cathode tool and the specimen anode. $\mathrm{NaCl}$ aqueous liquid has been used as an electrolyte at a range of speed (8-12 1/min) which passes within the inter-electrode gap (1 $\mathrm{mm})$. Generally, current density was ranged to be 0.5 to 1.1 Amperes per mm square. In all cases, the anodic dissolution rate found to be depending on the metal electrochemical properties, electrolyte status in addition to the electric current/voltage supplied [21]. The metal removal rate (MRR) and dissolution rate calculations have been carried out as follows [18]:-

$$
\begin{aligned}
& \operatorname{MRR}=\frac{\mathrm{W}_{\mathrm{b}}-\mathrm{W}_{\mathrm{a}}}{\text { time }} \quad\left(\frac{\mathrm{g}}{\min }\right) \\
& \operatorname{MRR}\left(\frac{\mathrm{cm}^{3}}{\mathrm{sec}}\right)=\frac{M R R(\mathrm{~g} / \mathrm{sec})}{\rho}
\end{aligned}
$$


Dissolution rate $=\frac{M R R\left(\mathrm{~cm}^{3} / \mathrm{sec}\right)}{A}$

Where:-

$\mathrm{W}_{\mathrm{b}}$ : workpiece weight before performing the machining process

$\mathrm{W}_{\mathrm{a}}$ : workpiece weight after performing the machining process

A: area of the cathode.

\section{Results and discussion}

\section{ANOVA output}

According to the analysis of the investigated responses by the present software (DOE), the fit summary output implies that the quadratic model is significant for all models used herein. Therefore, it can be employed for further analysis. All tests were carried out on the responses using the considered software such that; lack of fit test, the test for significance of the regression models, the test for significance on individual model coefficients. In addition, choosing the step-wise regression method allowed automatic elimination for any insignificant model term. Table 3 and Table 4 represent the ANOVA tables for MRR and dissolution rate models which outline the analysis of variance of each response as well as show the significant model terms. The same tables show also the other adequacy measures R2, Adjusted R2 and Predicted R2. The entire adequacy measures are close to 1 , which is in reasonable agreement and indicates adequate models [22, 23].The Adequate Precision compares the range of the predicted value at the design points to the Average Prediction Error. In all cases the value of Adequate Precision are dramatically larger than 4. An Adequate Precision Ratio above 4 indicates adequate model discrimination [23]. The Analysis of variance in Table3 indicates that all the process variables have a considerable effect on the MRR model. In fact, Table 3 indicates that the crucial factor that affects the MRR is the voltage since the F-value is 921.91 wherein the electrolyte concentration parameter is shown to be of less effect on the MRR model. A considerable effect for the flow rate parameter has been obtained as well. No significant effect for the parameter interaction has been observed for this model. All the R squares for this model were close to one and good adequate precision of 61.421 has been obtained as well. Table 4 implies the effect of the process parameters on the dissolution rate model. The voltage has been seen to be the prominent factor that affects the dissolution rate since the F-vale is 1608.34. Wherein, the flow rate and the electrolyte concentration showed a less effect on the dissolution rate models. For the purpose of reducing cost, energy and time a mathematical models have been built so as to prevent repeat additional experiments for other input values. Furthermore, this can lead to predict MRR and dissolution rate so as to develop a model that would be concluded into the optimization step at a later stage.

According to the DOE software, the final mathematical models in terms of coded factors can be represented by equations 4 and 5 .

Table 3.ANOVA for MRR model.

\begin{tabular}{|c|c|c|c|c|c|l|}
\hline & Sum of & & Mean & $\mathrm{F}$ & $\begin{array}{c}\mathrm{p}- \\
\text { value }\end{array}$ & \\
\hline Source & Squares & df & Square & Value & $\begin{array}{c}\text { Prob > } \\
\mathrm{F}\end{array}$ & \\
\hline Model & 0.072 & 6 & 0.012 & 334.92 & 0.003 & significant \\
\hline A-voltage & 0.033 & 1 & 0.033 & 921.91 & 0.0011 & \\
\hline B-Flow rate & 0.015 & 1 & 0.015 & 414.12 & 0.0024 & \\
\hline C-salt & 0.023 & 1 & 0.023 & 657.37 & 0.0015 & \\
concentration & $\begin{array}{c}6.41 \mathrm{E}- \\
05\end{array}$ & 1 & $\begin{array}{c}6.41 \mathrm{E}- \\
05\end{array}$ & 1.8 & 0.3118 & \\
\hline AB & $6.41 \mathrm{E}-$ & 1 & $\begin{array}{c}6.41 \mathrm{E}- \\
05\end{array}$ & 1.8 & 0.3118 & \\
\hline AC & 05 & & & & \\
\hline BC & $6.41 \mathrm{E}-$ & 1 & $6.41 \mathrm{E}-$ & 1.8 & 0.3118 & \\
\hline Residual & $7.12 \mathrm{E}-$ & 2 & $3.56 \mathrm{E}-$ & & & \\
& 05 & & 05 & & & \\
\hline Cor Total & 0.072 & 8 & & & & \\
\hline
\end{tabular}

Table4. ANOVA for dissolution rate model.

\begin{tabular}{|l|r|r|r|l|l|l|}
\hline & Sum of & & Mean & F & p-value & \\
\hline Source & Squares & df & Square & Value & $\begin{array}{l}\text { Prob > } \\
\text { F }\end{array}$ & \\
\hline Model & 0.51 & 7 & 0.073 & 297.71 & 0.0446 & significant \\
\hline A-voltage & 0.4 & 1 & 0.4 & 1608.34 & 0.0159 & \\
\hline B-Flow rate & 0.043 & 1 & 0.043 & 175.17 & 0.048 & \\
\hline $\begin{array}{l}\text { C-salt } \\
\text { concentration }\end{array}$ & $2.61 \mathrm{E}-03$ & 1 & $\begin{array}{r}2.61 \mathrm{E}- \\
03\end{array}$ & 10.57 & 0.19 & \\
\hline AB & 0.016 & 1 & 0.016 & 64.01 & 0.0792 & \\
\hline AC & 0.025 & 1 & 0.025 & 100.02 & 0.0634 & \\
\hline BC & $3.03 \mathrm{E}-03$ & 1 & $\begin{array}{r}3.03 \mathrm{E}- \\
03\end{array}$ & 12.25 & 0.1771 & \\
\hline A $^{\wedge}$ & $5.77 \mathrm{E}-03$ & 1 & $\begin{array}{r}5.77 \mathrm{E}- \\
03\end{array}$ & 23.36 & 0.1299 & \\
\hline $\mathrm{B}^{\wedge 2}$ & 0 & 0 & & & & \\
\hline $\mathrm{C}^{\wedge 2}$ & 0 & 0 & & & & \\
\hline Residual & $2.47 \mathrm{E}-04$ & 1 & $\begin{array}{r}2.47 \mathrm{E}- \\
04\end{array}$ & & & \\
\hline Cor Total & 0.51 & 8 & & & & \\
\hline
\end{tabular}


Final mathmatical models in Terms of Coded Factors:

$\mathrm{MRR}=0.31+0.064 \mathrm{~A}+0.043 \mathrm{~B}+0.059$

$\mathrm{C}+2.830 \mathrm{E}-003 \mathrm{~A}$ B $-3.113 \mathrm{E}-003 \mathrm{~A} \mathrm{C}$ $+3.113 \mathrm{E}-003 \mathrm{~B} \mathrm{C}$

(4)

Dissolution rate $=1.82+0.22 \mathrm{~A}+0.074$ $\mathrm{B}+0.020 \mathrm{C}+0.044 \mathrm{~A} \mathrm{~B}+0.061 \mathrm{~A} \quad \mathrm{C}-0.021 \mathrm{BC}$ $-0.081 \mathrm{~A} 2$

(5)

\section{Model validation}

The next step is to predict and confirm the enhancement of the response using the optimal level of the ECM process parameters. Figure 2 and Figure 3 show the relationship between the actual and predicted values of MRR and dissolusion rate respectively. These figures invistigated that, the developed models are adequate because the residuals in prediction of each response are negligible, since the residuals tend to be close to the diagonal line as this can be seen clearly in Figure 2 and Figure 3.

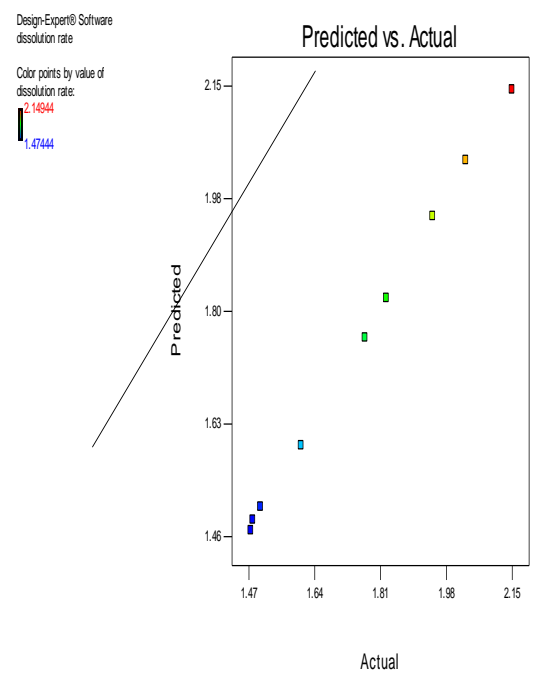

Figure 3: scatter diagram for dissolution rate model

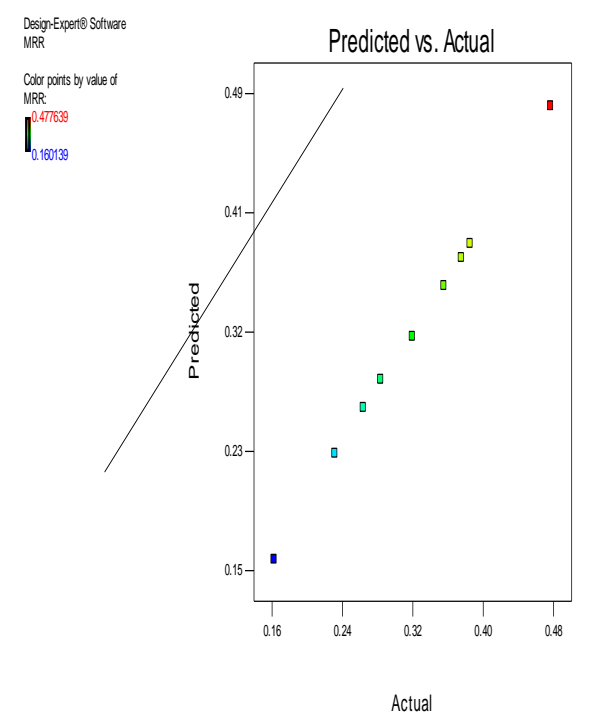

Figure 2: scatter diagram for MRR

\section{Influence of the process parameters on the response \\ Metal removal rate (MRR)}

Figure 4 shows the effect of the process parameters on the MRR. Accordingly, the $x$ axis represents the voltage and the $y$-axis represents the flow rate. More clear vision can be obtained by the 3D contour graph shown in Figure 4 as this illustrates the same process parameters effect on the MRR itself. The results, obtained from both Figure 4 and Figure 5 state that, increasing the value of the voltage, flow rate speed and electrolyte concentration can lead to significant increment in the MRR. The voltage, as process parameters, has been investigated to be a crucial factor in the enhancement of MRR. This can be illustrated due to; the ECM operations begins at certain $\mathrm{A} / \mathrm{cm}^{2}$ and the current density increases almost linearly with the potential for a currents greater than $5 \mathrm{~A} / \mathrm{cm}^{2}$ [24-26]. Hence, when the voltage is maxima $25 \mathrm{~V}$ the MRR reaches its maximum value of $0.477 \mathrm{~g} / \mathrm{min}$ as this was carried out for all experiment considered in this work. In other word, the voltage increasing will lead to further increment in the current density and hence more required weight reduction is obtained. This has found to be in total agreement with the ANOVA analysis listed in 
Table 3 since the voltage was previously shown to be a prominent factor in affecting the MRR. But, still a considerable effect in the MRR value can be seen with increasing the value of the flow rate and the electrolyte concentration as well. However, when this corrosion process is resuming a hole or in other word the required machining process has been obtained. More confirmation, to the results presented in Figure 3 and Figure 4, can be investigated due to Figure 6 which shows a visual inspection images. This figure represents a comparison between the recognized experiments achieved in this work in terms of the MRR with respect to the asreceived material. Hence, the considered inspection in this work showed that the difference between experiments 1, 5, 9 was clearer to be seen visually.

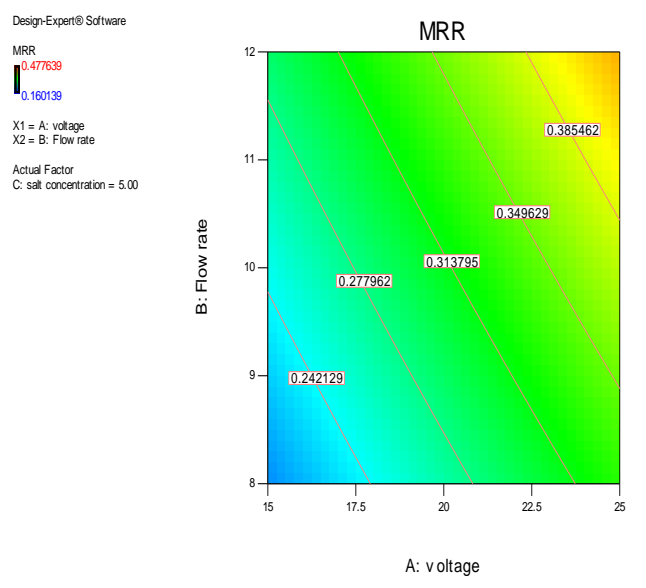

Figure 4: shows the effect of the ECM process parameters on MRR

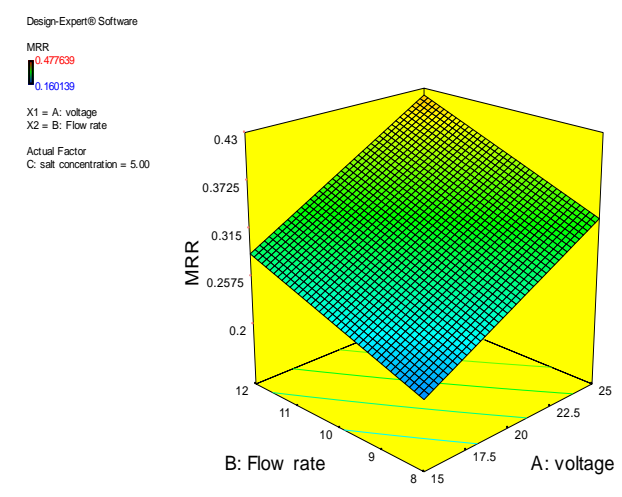

Figure 5: 3D surface and contour graph shows the effect of the ECM process parameters on MRR
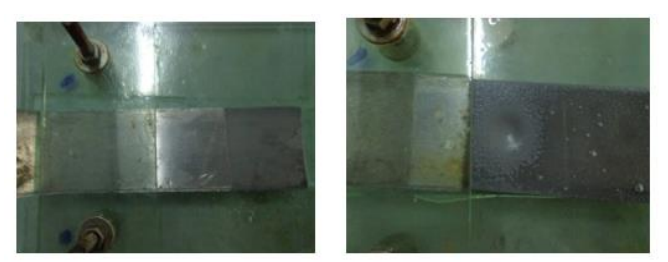

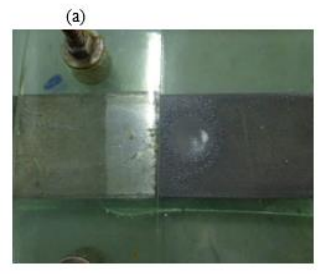

(c)

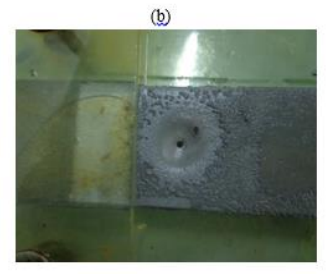

(d)
Figure 6: shows (a) as received material , (b) experiment 1 , (c) experiment 5 , (d) experiment

9

\section{Dissolution rate}

The influence of the process parameters (i.e. electrolyte concentration, voltage and flow rate speed) on the response variable (dissolution rate) have been investigated in this work as well. Figure 7 and Figure 8 imply the contour and three dimensional surface plots for the dissolution rate respectively. In usual, two of the three independent variables are kept constant at center level. Figure 7 and Figure 8 clearly reveals that, MRR is in general increases with all the process parameters considered in this work. In comparison to the other process parameters, the voltage has been found to be of significant effect on the dissolution rate. This has been in agreement with ANOVA analysis shown in Table 4. In fact, increase the applied voltage and feed rate has led to increase the current density in the inter-electrode gap with the consequent rapid anodic dissolution, and hence MRR increases [27]. This has been seen evidently due to the considered experiments herein. Thus, maximum dissolution rate of $2.149 \mathrm{~mm} / \mathrm{min}$ has been obtained at maximum voltage of $25 \mathrm{~V}$ as the flow rate speed was $12 \mathrm{l} / \mathrm{mm}$. wherein the value of the dissolution rate has been reduced to be $1.944 \mathrm{~mm} / \mathrm{min}$ when there was a reduction in the flow rate. But, still from different point of view increase the electrolyte concentration can lead to increase the speed of the chemical interaction and hence improve the amount of MRR [28]. 


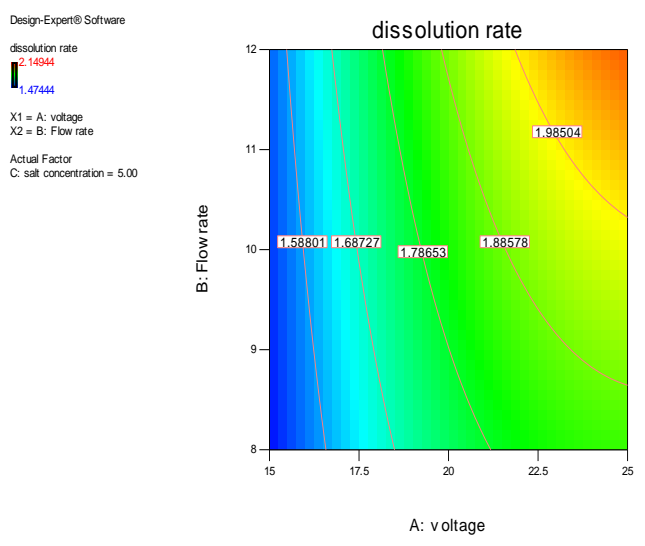

Figure 7: shows the effect ECM process parameters on dissolution rate

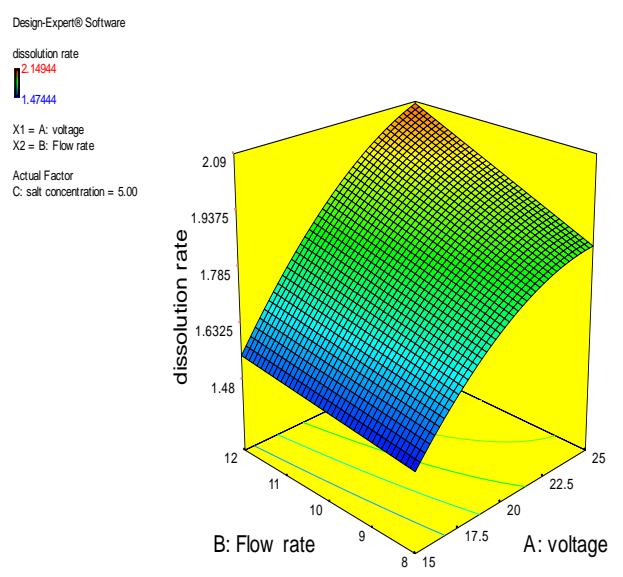

Figure 8: 3D surface and contour graph shows the effect ECM process parameters on dissolution rate

\section{Perturbation plots}

Figure 9 and Figure 10 are a perturbation plots showing the effect of all parameters on the MRR and dissolution rate respectively. The perturbation plot permits the influence of all the variables at a particular point in the design space to be compared. This kind of display does not imply the influence of interactions. The lines show the behavior of each variable while holding the others in a constant ratio (center point by default). When there is more than one variable, this type of display can be used to investigate those variables that most affect the response. According to Figure 9, it is evident that a sharp relation between all the process parameters and the MRR can be investigated. Hence, changing any of the process parameters from its lowest value to the highest value would result in an increase in MRR. Precisely, this perturbation plot observed to be verification to the results obtained from the ANOVA analysis shown in Table 3. Since the voltage found to be a dominant factor that affect the MRR significantly. This result states also, the increase in the flow rate speed and the electrolyte concentration can lead to a reasonable increment in the MRR. The relationship between the process variable with the dissolution rate tends to show the same relation with the MRR and this has been clarified in Figure 10. Hence, the voltage parameter once again shows the greatest effect on the dissolution rate as compared to the other process parameters. Further to the effect on the dissolution rate, this result has been confirmed by the ANOVA analysis listed in Table 4 as well.

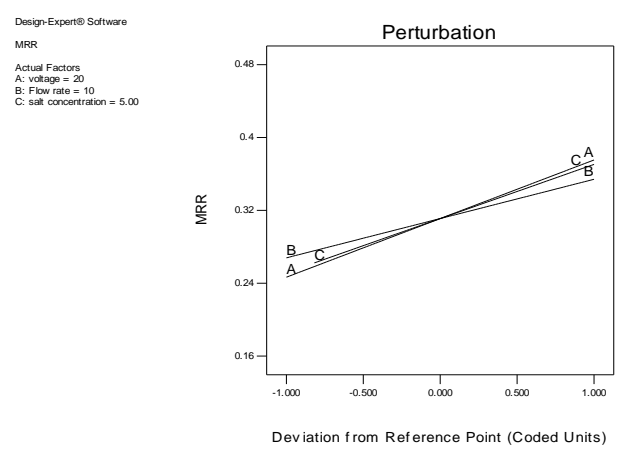

Figure 9: perturbation plot shows the effect of all the ECM process parameters on the MRR at the same time

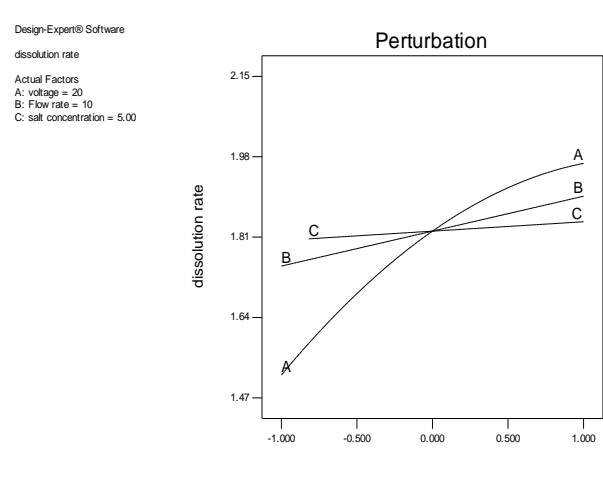

Figure 10: perturbation plot shows the effect of all the ECM process parameters on the dissolution rate at the same time 
Table 5 optimization criteria and importance.

\begin{tabular}{|c|c|c|c|c|c|}
\hline \multirow{3}{*}{$\begin{array}{l}\text { Parameter } \\
\text { or response }\end{array}$} & \multirow{2}{*}{ limits } & \multicolumn{2}{|c|}{ importance } & \multicolumn{2}{|c|}{ Criteria } \\
\hline & & & & Without & With \\
\hline & lower & upper & & restrictions & restrictions \\
\hline Voltage & 15 & 25 & +++ & In range & Maximize \\
\hline $\begin{array}{l}\text { Flow rate } \\
\text { speed }\end{array}$ & 8 & 12 & +++ & In range & Maximize \\
\hline $\begin{array}{l}\text { Electrolyte } \\
\text { concentration }\end{array}$ & 3 & 7 & +++ & In range & In range \\
\hline MRR & 0.16 & 0.477 & +++++ & In range & Maximize \\
\hline $\begin{array}{l}\text { Dissolution } \\
\text { rate }\end{array}$ & 1.474 & 2.149 & +++++ & In range & Maximize \\
\hline
\end{tabular}

Table 6 Shows the twelve optimal solutions based on the first Criterion

\begin{tabular}{|c|c|c|c|c|c|c|}
\hline Number & voltage & $\begin{array}{c}\text { Flow } \\
\text { rate }\end{array}$ & $\begin{array}{c}\text { salt } \\
\text { concentration }\end{array}$ & $\begin{array}{c}\text { MRR } \\
(\mathrm{g} / \mathrm{s})\end{array}$ & $\begin{array}{c}\text { dissolution } \\
\text { rate }\end{array}$ & Desirability \\
\hline 1 & 23.24 & 10.1472 & 4.8 & 0.350305 & 1.93575 & 1 \\
\hline 2 & 20.075 & 10.286 & 4.14 & 0.29245 & 1.82904 & 1 \\
\hline 3 & 15.974 & 9.114 & 6.79 & 0.295242 & 1.55549 & 1 \\
\hline 4 & 21.267 & 8.292 & 3.62 & 0.251268 & 1.76459 & 1 \\
\hline 5 & 20.052 & 10.278 & 6.3 & 0.356479 & 1.84665 & 1 \\
\hline 6 & 23.69 & 9.4112 & 4.65 & 0.335427 & 1.90027 & 1 \\
\hline 7 & 15.941 & 11.0548 & 3.88 & 0.244683 & 1.63066 & 1 \\
\hline 8 & 16.564 & 11.282 & 5.95 & 0.323398 & 1.64147 & 1 \\
\hline 9 & 22.873 & 8.5908 & 4.19 & 0.29405 & 1.82641 & 1 \\
\hline 10 & 18.712 & 9.6444 & 5.07 & 0.288936 & 1.74879 & 1 \\
\hline 11 & 15.215 & 8.142 & 6.71 & 0.262725 & 1.48945 & 1 \\
\hline 12 & 19.12 & 8.3912 & 4.05 & 0.238138 & 1.71515 & 1 \\
\hline
\end{tabular}

Table 7 Shows the twelve optimal solutions based on the second Criterion

\begin{tabular}{|c|c|c|c|c|c|c|}
\hline Number & voltage & $\begin{array}{c}\text { Flow } \\
\text { rate }\end{array}$ & $\begin{array}{c}\text { Electrolyte } \\
\text { concentration }\end{array}$ & MRR & $\begin{array}{c}\text { dissolution } \\
\text { rate }\end{array}$ & Desirability \\
\hline 1 & 24.9998 & 12 & 7 & 0.480781 & 2.14388 & 0.997 \\
\hline 2 & 25 & 11.9993 & 7 & 0.480645 & 2.14373 & 0.997 \\
\hline 3 & 25 & 12 & 6.99 & 0.480538 & 2.14364 & 0.997 \\
\hline 4 & 24.9932 & 12 & 7 & 0.480696 & 2.14365 & 0.997 \\
\hline 5 & 25 & 12 & 6.98 & 0.48021 & 2.14331 & 0.997 \\
\hline 6 & 25 & 11.9999 & 6.95 & 0.479331 & 2.14243 & 0.997 \\
\hline 7 & 24.9637 & 12 & 6.96 & 0.479167 & 2.14152 & 0.996 \\
\hline 8 & 25 & 11.9589 & 7 & 0.479775 & 2.14189 & 0.995 \\
\hline 9 & 25 & 12 & 6.82 & 0.475492 & 2.13858 & 0.993 \\
\hline 10 & 25 & 11.9058 & 6.99 & 0.478201 & 2.13904 & 0.991 \\
\hline 11 & 25 & 12 & 6.67 & 0.470844 & 2.13393 & 0.986 \\
\hline
\end{tabular}

\section{Conclusions}

The electrochemical machining for 6061 aluminum has been studied experimentally and analyzed statistically and the following points are generally concluded:

i) $\mathrm{ECM}$ seen to be a successful technique for machining the 6061 aluminum metal.

ii) The developed models can adequately predict the responses within the factors domain.

iii) By employing the DOE approach, it is possible to achieve the best operating parameter window and then develop models to control the ECM parameters.

iv) According to ANOVA analysis, all the considered models were significant and the voltage parameter was shown to be a prominent factor that affect the responses strongly.

v) A considerable effect for the flow rate and electrolyte concentration have been concluded, since the change in the flow rate speed can lead to more mobility of ions and this increases the speed of the chemical reaction or otherwise leads to more MRR and dissolution rate.

\section{References}

[1]. H. Hocheng, P.S. Pa. Effective form design of electrode in electrochemical smoothing of holes. International Journal of Advanced Manufacturing Technology 21, (2003),

995-1004.

[2]. P.S. Pa. Mechanism design of magneticassistance in surface finishing of endturning. Journal of Advanced Mechanical Design, System, and Manufacturing 2, (2008),

$587-596$.

[3]. P.S. Pa. Synchronous finishing processes using a combination of grinding and electrochemical smoothing on end-turning surfaces International Journal of Advanced Manufacturing Technology 40, (2009), 277-285. 
[4]. Y. Tang. Laser enhanced electrochemical machining process". Materials and manufacturing Processes 17, (2002), 789796.

[5]. J. Kozak, K.E. Oczos, Selected problems of abrasive hybrid machining, Journal of Material Processing Technology. 109, (2001), 360-366.

[6]. P.S. Pa. Design of effective plate-shape electrode in ultrasonic electrochemical finishing. International Journal of Advanced Manufacturing Technology 34(2007), 70-78.

[7]. P.S. Pa. Super finishing with ultrasonic and magnetic assistance in electrochemical micro-machining, Electrochimica Acta 54 (2009), 6022-6027.

[8]. J. Kozak. Mathematical models for computer simulation of electrochemical machining process. J. Mater. Process. Technol. 76 (1998), 170-175.

[9]. A.R. Mount, D. Clifton, P. Howarth, A. Sherlock. An integrated strategy for characterisation and process simulation in electrochemical machining. J. Mater. Process. Technol. 138 (2003), 449-454.

[10]. S.J. Ebeid, M.S. Hewidy, T.A. EI-Towell, A.H. Youssef. Towards higher accuracy for ECM hybridized with low frequency vibrations using the response surface methodology, J. Mater. Process. Technol. 149 (2004), (432-438).

[11]. A. Pramanik, A. K. Basak, M. N. Islam. Effect of reinforced particle size on wire EDM of MMCs International Journal of Machining and Machinability of Materials. 17(2015), 139-149.

[12] A. Pramanik. Electrical discharge machining of MMCs reinforced with very small particles. Materials and Manufacturing Processes. DOI: 10.1080/10426914, 2015.

[13]. A. Pramanik. Developments in the nontraditional machining of particle reinforced metal matrix composites.
International Journal of Machine Tools and Manufacture, 86(2014), (44-61).

[14]. S. Srkar, S. Mitra, A. B. Bhattacharya. Parametric analysis and optimization of wire electrical discharge machining of $\gamma$ titanium aluminide alloy". Journal of Materials Processing Technology, 159 (2005), (286-294).

[15]. T. A. Spedding, Z. Q. Wang. Study on modeling of wire EDM process. Journal of Materials Processing Technology, 69 (1997),

(18-28).

[16]. Y. S. Liao, J. T. Huang, H. C. Su. A study on the machining-parameters optimization of wire electrical discharge machining $[\mathrm{J}]$. Journal of Materials Processing Technology, 71 (1997), (487-493).

[17]. H. K. Dave, V. J. Mathai, P. Desaik, H. K. Raval. Studies on quality of microholes generated on Al 1100 using micro-electrodischarge machining process. The International Journal of Advanced Manufacturing Technology no 7 (2013), (127-140).

[18]. M. Burger, L. Koll, E.A. Wernera,A. Platz. Electrochemical machining characteristics and resulting surface quality of the nickel-base singlecrystalline material LEK94, J. Manuf. Processes. 14(2012), (62-70).

[19] D. Bahre, O. Weber, A. Rebschlager. Investigation on pulse electrochemical machining characteristics of lamellar cast iron using a response surface methodology based approach, Procedia CIRP 6(2013), (363-368).

[20]. Sekar, T., Marappan, R. Experimental Studies On Effect Of Tool Geometry Over Metal Removal Rate In ECM Process" Journal Nonconventional Technologies no. 3(2017), (107-110).

[21]. Rajurkar, K.P., Sundaram, M. M., Malshe, A. P. Review of Electrochemical and Electrodischarge Machining. The Seventeenth CIRP Conference on Electro Physical and Chemical Machining (ISEM). Procedia CIRP 13 - 26 (6), (2013). 
[22]. D. C. Montgomery. Design and Analysis of Experiments. 2nd Edition, John Wiley \& Sons, New York, 1984.

[23]. Design-Expert software. V7, user's guide, Technical manual, Stat-Ease Inc., Minneapolis, MN, 2005.

[24]. Rosenkranz, C., Lohrengel, M.M. and Schultze, J.W. Electrochim Acta205 (50), 2009.

[25]. Lohrengel, M.M., Klüppel, I., Rosenkranz, C., Bettermann, H. and Schultze J.W. Electrochimica Acta ". 3203 (48 ), 2003.

[26]. Lohrengel, M.M., Rataj, K.P., Münninghoff, T. Electrochemical Machining-mechanisms of anodic dissolution, Electrochimica Acta, 2015.

[27]. B.R. Sarkar, B. Doloi, B. Bhattacharyya. Parametric analysis on electrochemical discharge machining of silicon nitride ceramics, Int. J. Mach. Tools Manuf. 28 (2006) 873-81.

[28]. Lohrengel, M.M., Klüppel, I., Rosenkranz, C., Bettermann, H. and Schultze J.W. Electrochimica Acta. 3203 (48), 2003.

List of symbols and abbreviations

\begin{tabular}{|l|l|}
\hline DOE & Design of experiment \\
\hline ANOVA & Analysis of variance \\
\hline ECM & Electrochemical machining \\
\hline MRR & Metal removal rate \\
\hline IEG & Iter-electrod gap \\
\hline $\mathrm{V}$ & Voltage \\
\hline $\mathrm{Wa}$ & $\begin{array}{l}\text { the weight of the workpiece after } \\
\text { carrying out the machining } \\
\text { process }\end{array}$ \\
\hline $\mathrm{Wb}$ & $\begin{array}{l}\text { the weight of the workpiece } \\
\text { before carrying out the machining } \\
\text { process and }\end{array}$ \\
\hline
\end{tabular}

